\title{
西北大學應怎樣開展科學研究工作·
}

\author{
岳 劼 恒
}

（西北大學敉弱带）

\section{一 科罢研究在西北大基本情况}

在西北大學開展科學研究工作是有初步的條 件的, 全校 246 位敉師中, 過去會作研究工作並 皘累有一些經驗者不少。在一般自然科學方面， 由於設借條件較美, 淮行規模較大的、需要高度 精確測量的研究工作, 確有困難。但是在有地區 性的自然科學方面的研究, 以及故酸經營、企業 管理等技術性的社會科學方面的研究, 則又具有 一定的條件，可以逐步開展。一年來，我們在這 一些方面已經做了若千工作。例如：地質系敉授 在 1953 年下牛年參加了西安市基本建設工地的 地質調左、水文地質調圧、地震烈度級數調查等 研究工作, 提供了一些有價值的意見; 又接受了 西北石油地質局的委甜，合作鑑定大量古生物化 石標本。化學系敉授在 1953 年寒假中接受西北工

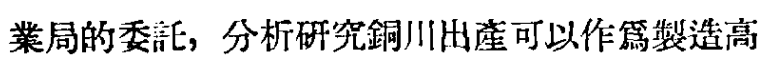

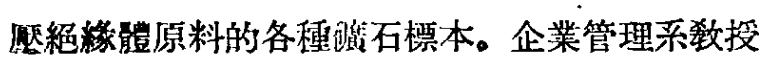

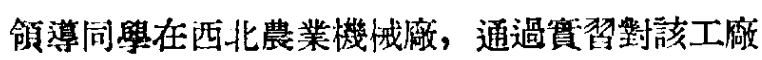
的工時浪費現象，根據技術定額測定作了检查。 歴史系数授作了不少有關資料的研究工作, 菟集 整理了若干中國史料，並接受了中國利學院的委 部, 調查西安附近出土的秦漢陶器, 已寫成正續 兩編, 對考古研究工作, 供給了若干材料。但造 些研究工作, 完全是郄師們自發進行的, 或者是 礁允校外機構的要求而進行的, 在學校領導 方 面，完全沒有加以組織领導，得不到應有的支持 和鼓棘，由而收效不大，没有㙷著的進展。

然而一年以來, 利學研究問題, 由於中央高 等数育部、中國利學院各方酥的大力號召, 以及 敉祭改革工作上的需票，在西北大學敉師中間引 起了强烈的反虑。經過一年來的酮酷討論, 對科 學研究的認践和看法, 基本上有了改變, 若干不
正確的思想得到了批制和科正，篇今媵淮一步開 展科學研究工作，在思想上鈰平了道路。

首先, 在 1953 年中國科學院訪蔂代表国返

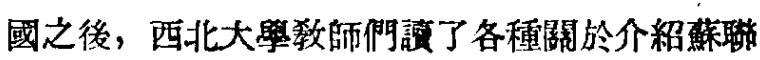
科祭研究工作的報告, 對於社會主義國家科學進 步之迅速, 對於掌握馬克思列蜜主義後進行研究 工作之有力, 普遍地引起了詈仰和菜慕。大家一

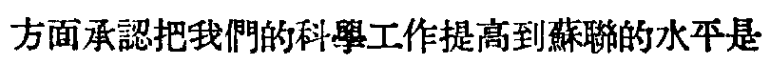
一件極篇熯䤠的任務，但想到有黨和政府的正磪 領运, 鮛聯無私的國際主義的協助, 造亚不是可 望不可及的目標, 問題在於如何結合我椚的情况 學習蘇聯。由此, 對我國的科學研究工作, 普遍 地樹立了信心，時刻淮借着寥加䄐一工作。

其次, 在 1953 年 9 月全國棕合性大學會議之 後, 明確了綜合性大學的任務主要是篇祖國培養 科學研究人材。這一號召, 在敉師中引起了更大 震動。想要培養學生成第科學研究人材, 自己不

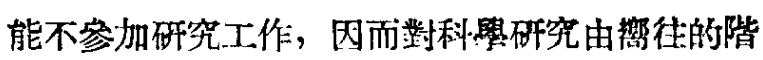

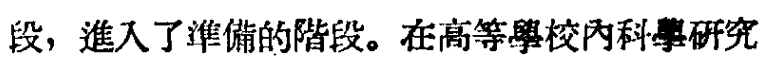
工作的範圍，成篇當時争論的中心。由於對各種 交件學晳不深刻, 最初意見很不統一, 往往㗶生 相互矛盾的解釋。有人把科學研究看得太低，以

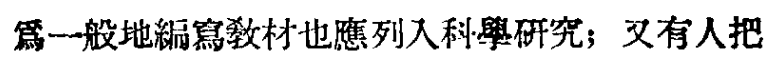
科學研究看得太高, 以第科學研究應有一定的學 行上的重要性, 不能使科樂研究一般化。造兩種 看法都是有偏美的。對科學研究如何結合生應的 問題, 教師門也有不同的看法。有的看得太近，以 篇必須與生產技術遖接有關，甫算得結合生産， 有的父離開賴際太遠, 倾问於篇研究而研究, 考

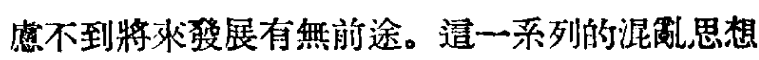
狀况, 經過一年爽的反锣討論, 文件學替, 最後 達到一教的認䋘。 
1953 年署假青島敉學計劃討論會，對若干專 莱草提了兩種不同的敉學計劃。一般大學適用的 第二種計劃，要求較低，專門化的課程没有列 入,科舉研究對敘學工作在表䤄上關係不大。1954 年 6 月，中央高等新育部在釉聯專家指導之下， 另制定化鼻、物理等専業致學計劃。把嵬成學生 猛立思考、摆立工作的精神，賁徽在整個課程計 捚中。事門化課程、專題討論、課程論文、畢業 論文，成第一專業課程在三、四年級的主要內 客。事門化課程必須涉及科量的最新成就; 潗備 詥文必須參考有關的各種科學交獻。指導學生淮 行造一類工作，師必須自己先鑽進去。通就使 綜合大學會議所指出的培食研究人材的任務, 有 了具䯏內容，而敉師們展開研究工作，也就成篇 完成数工作必不可少的條件之一。因而西北大 哥称師對科學研究工作的重要性有了進一步的認

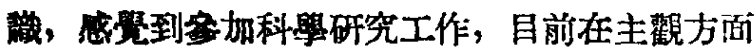
不是願意或不頋意的問題，在客觀方面不是可能 舆不可能的問題; 想要完成棕合大學培奉研究人 材的任揫，想要使自己数出的學生能適合於祖國

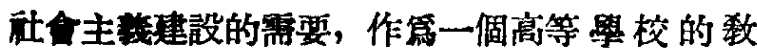
師, 就必須案加科學研究工作。客觀條件是可以 逐濑具借的，政府正在大力給我校以物資的供

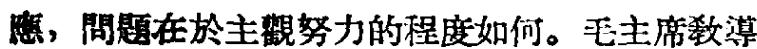
我門: “.......我們不熟㚙的東西正在强 迫 我們去 做。……我們必須克服困難，我們必須擧會自己 不住的東西。”本着造一精神，没有不可克服的困 暙。革命事業多牛是由無到有, 由小到大。何况 科學研究在西北大眾已經或多或少具備有初步條 件，我們一定能走向成功。

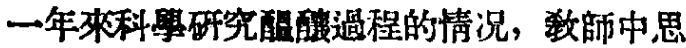
想的演變，西北大學和其他高等學校大致是相同 的。總的講起來：思想澄清了，認識一致了，第 今後展開研究工作在思想和認識上仅定了稳固的 根基。但據我個人的看法，有些人還有顧急。過 去會作過科軍研究工作的人，對自己過去的成 就，块乏信心，不明確是否離生產㳋際太薏，現

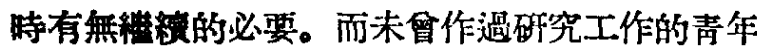
数師對科學研究雖然有熱情、有信心，但感學缺

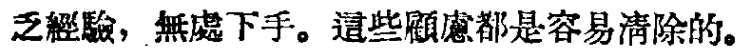
明白了科繁工作者應該在漫根本而文最廣泛的範

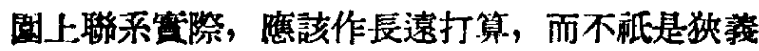

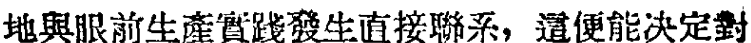

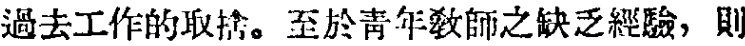
篇不可避色的事䁈。這就有赖於数所之間的合 作，有經驗的致帥指莎毒年敉師，青年数師筫重 有經驗的敉師。在規模較大的研究工作中，㑭責

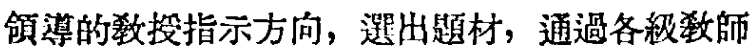
以及砰究生，僡授經驗，分工合作。在有關自然 科臬政究的技術操作与，青年具有特長，在工作 强度上也超過年老教顾。如果领澱得法, 缺乏經 驗的青年敉師就能逐溸掌握從事研究工作的技街 和方法。

\section{二 進行科鼠研究應有的準備工作}

在西北大典開展科學政究工作，已經超過了 一般的號召階段，必須開始進行貫際工作。一年 棑，我們领導上着獀犯了穞步不前的錯誤。棕合 大學會議之後，我們制定全校工作計劃時，只提 到隻借利學研究，而事筫上.潐偖工作進行得很有 限，今後必須有所改變。躀了郭沭落院長“關於 中國科院的基本情况和今後工作任務的報告”, 並寥考了各高等學校有關科學研究工作的文件， 在西北大學展開科學研究工作，我以篇應採取以 下步频:

（1）做好調查工作：首先是人力的調查。 應全面地調查每位敎師的專長、過去曾作過的研 究以及今後擬繼續的研究工作。整頓陵伍，摸清

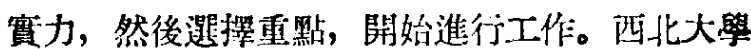
各数研組、各敎師敉學任坦很不本衡，應賞調查

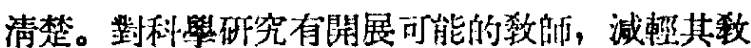
學负担。各位教師的致學情况也有很大的美别。 有些課程敎師巳担任多次，借課需要㭙間較少; 有些課程因敎師初次担任，內容㔯有問題，借課 需要很多的時間。對於這些不同的情况，科祭研 究的要求, 礁有所區别, 以要畸輕畸重, 顧此失 彼，也給今後貫行工作量制度打下基礎。其次篇 物力的調查。我校儀器設備, 四年來政府大力配 備, 已堷加不少, 其中一部分較篇精確的義器, 適宜於進行研究工作之用，但可能零件不全或 少配合使用的儀器，必須詳篇調查。一方面可以 根據已有設请，潐供進行可能的研究工作，一方

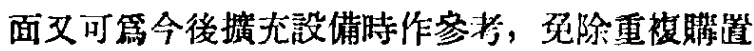
等浪費現象。圖書期刊也必要加以调查，淮行㸴

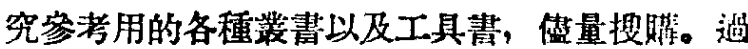


期期刊, 由於徵求不易, 價格過昂, 應建議有關 方面大量影印。現已影印出版的十餘種, 均自 1930 年起, 建議應再提前 20 年, 同時種類 也應 多多垤加。遵是進行研究客觀條件上必不可少的 一部分。

（2）加强計割性: 人力物力調查清楚之 後, 由每位敉師起, 制定储人研究工作計劃, 通 過敉研組與系，綜合第全校的工作計劃。根據客

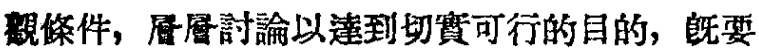
適合於科學研究的標淮, 又不能好高憼遠, 超過 我校客觀條件，並且在全校範園之內，必須摆取 重點, 在人力物力上, 多加以照稓。在每一系或 研租內, 必須集中力量, 研究互相率涉的一系 列問題，分工合作，弡揮集體力量。更應注意在 開始階段, 要求不能過急, 由初級到高級, 由解 决個别問題棈累到較有系紶的工作。各種計劃, 規定必須具體, 對於每一研究工作, 題村、進程、 完成日期、需要資料（或經費）、主要工作人等, 必須詳列, 以便检查。造一點是必須特別强調 的。鹤型的科學䂯究工作者，大都犯着自由主䉝， 走到那赛就是那裹, 常常牛途洏廢, 得不到任何 結果。紀律性與集體精神是作第一個新的利學工 作者必須具有的條件, 在科學㸴究工作中, 我們 必須質徹下去。

（3）加强等習: 在業務方面，必須更加强調 向蘇聯學替。蘇䧄的現代科學在每一部閌內都吸 收了全世界先進科學的成果, 而及嚴格地批制其 不正確部分。我國在過去革命時期, 在黨的領运 下, 吸取蘇聯的革命經驗而獲得成功, 現時又在 蘇聯無私的援助下，進行㖣會主義建設。作篇協 助建設工作的科學研究工作者, 如果對學習蘇聯 信心不足或用力不的，絕對不能保登科學工作能 與建設工作相結合。毛主席敎導我們，要誠心誠 意地學柏镍聯，這是我們每一個科學工作者必須 切賽賽行的。另一方面, 我們必須更加强調馬克

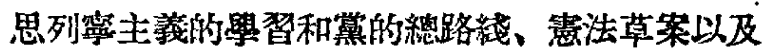
各項政策法令的悬習。用馬克思列寧主義武裝自 已，才能在學断上辩别唯物論與唯心論的思想，

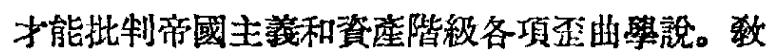
學改革是進一步的思想改透, 保登逪種改造的成

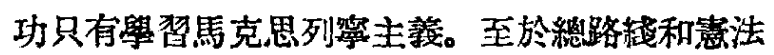

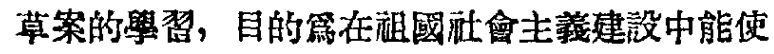

我們認識一致，步調一致。總路檍引运我們過波 到社會主義社會, 害法草案總結了我們炗命成功 的經驗，指出了今後在政治上、經㴼上必須要循 的途徑。科學工作者必須對緮路和密法草案有

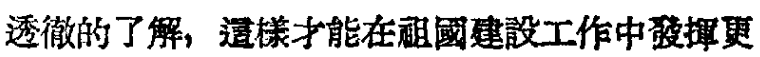
大的作用。

以上三項，霨在西北大學進行科祭研究首要 的準僃工作，奜校行政上必須特别地注意，大力 支持, 這樣才能給師師進行具體研究工作以有利 的條件，鼓踪敉師們的勇氣和信心，給開展科學 研究工作以好的開端。

\section{三敀棒進行科贯研究}

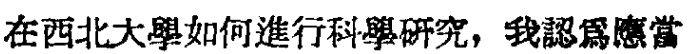
分三個方面:

（1）結合数學工作：在语等學校淮行科學研

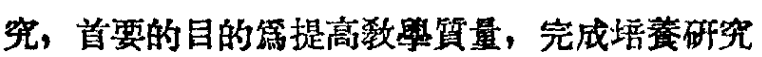
人材與敉藇人材的任矽。造就使學校內的科學研 究工作不同於科祭院稼屈的研究機檕, 也不同於 企業部門附設的研究機構。在創始階段，不能有 過高的要求。我以筬科悬研究工作可包括以下的 內容：如綜合大學會議所提出的，研究蘇聯材 而有獨到的深刻的見解，用以批制資本主䔐國家 的不正確的學說，或用我國的事例，来發堚充贲

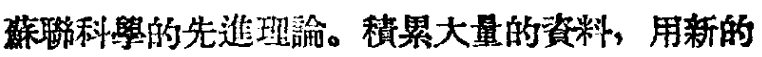
觀點、方法研究整理，竄出敉材。選搼某一有現 實意義的考據工作，寫出整理的材料。根據已知 的方法, 研究具有地區性的問題, 來哣富科學的 內容。分析研究某種原料的化學性買或物理性質, 因而斷定其應用的價值; 用精磪可的方法校蕉 各項基本量的單位（長數、温度、電量、能量等） 作雼工業上測量的標淮。其他如建立事門䐝驗室， 淮備專門化凟驗, 踓是探用已知的裝借, 但因篇 材料不资手或其他原因, 加以改裝修正, 也都可 以列篇研究工作。尤其重要的是，根㨲新的敩

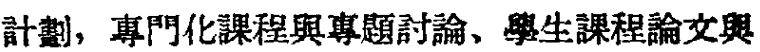
畢業論交，一、二年內在綜合大學各專業內必須

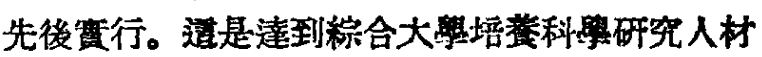
目標的唯一途徑, 而要做好逼一工作, 必須敉師 把自己的研究方向和專門化課程，專門望騟結合 起来。按照镍聯專家的意見，專門化課程應涉及有

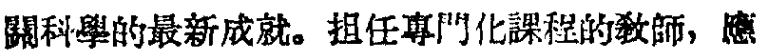

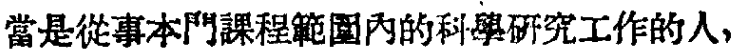
9 月號
科學通 報
- $\boldsymbol{T}$ 
或者至少是從事與此項課程相近的科學研究工作 的人，罜樣可以使學生認識逭一部分科學的最新 成就。在我校現有師資情况下，對於若干專業， 造些要求壝是過高的。但担任專門化課程以及專 門課程的铱䛲，必須把自己研究工作的方向，對 所敉的課程。也就是說, 在有關的課程範圍內, 選摆自己呼究的題材, 列篇最低的要求, 是非做 到不可的。

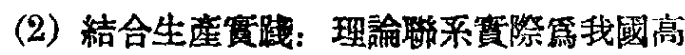
等悬校教育的基本原則。反脞在科研究工作 中, 如何和生產賽践相聯系, 是一偑頭等重要的 問題。工㟲興研究室結合起來，兩方酘的工作效 可同時提高。研究空的研究成果給工简以技術 上的指導，同時工湤給研究空以研究題材及物質 上的支援。如何聯采?工廠可以问棺等學校提出 它椚急待解決的迫切問題，问時高等䝿校的教師 也可以到工倣中去發現與自己業邪有關的問題。

自然, 高等學校不能解决工殿方酒提出的一切問

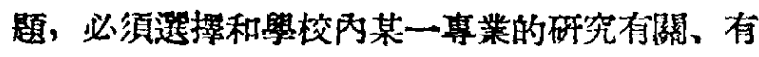
一定的科學意義、亚且篇工旗方面所不能解沈的 問題。一般的测量工作或分析工作，學校不能一 概接受，這種工作在改進生產技術上並無意義或

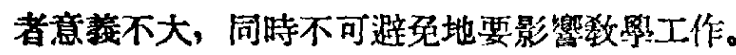
另一方面, 結合生産賀際的意我, 我椚也必須有 所辨别, 不能理解篇每一研究題目都要和生济直 接有關。目前似乎和生產無關而在將來可以和生 有關者，也都是結合生産的科學研究。我門都 知道法拉第、波波夫的研究工作，在最初和生座 宽際都有相當的距崔，但登展到後來，㳭入到生 迹部門，使人類的物質生活墢生了重大的改變。 在結合生圱迶一方面，我們學校有優越的環境， 荣聒期我們建立或改建的 141 項企業, 不少一 部分在西北區內, 将來必然會有一系列的科學問 题, 需要硼究解決的。例如對於各種原料物理性 筫和化學性颃的籃定, 以及分析提煉的研究, 這 些都不是單純的化驗工作，應篇我校物理學、化 舆等専業所接受。對於地質情况、土貿、水文的 考查, 踓有一般的方法可以隹用, 但因地區不同 有很大的差異, 必須因地制宜, 不等於簡單的测 量工作，也應篇我們地理、地質等專業所接受。 另外如各頊工故的企業管理中所發生的問題, 如 成本核算、支術定額等, 應篇剘經各專業所接
受。我們要主動地與政府主管部門取得聯系, 下

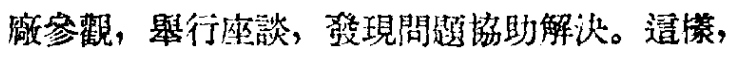
不只是促進了高等學校內的研究工作, 解让了生 部門發生的問題, 亚使科學工作者得以更有效 地寥加祖國建設工作。這是等一個科學工作者所 束心熱望的。

（3）結合將來中國利學院西北分院的中心工 作: 在蘇聯高等學校研究工作的題材中，一蔀分 第從科學院分得的若干有閶國上經济的重大問 題, 跹些間題的研究是在科學院統一㑔禁下有計 劃地進行的。我國將来地必須探用造一力域，才 能在全國範图內，分工合作，兑除工作上的重 複和人力浪費。而且在高等䀢校中，标在着一批 在數量上遠比科學院篬雄湶，在質量上也有一定 水潐的研究人材，订作科學院研究工作啲有力助

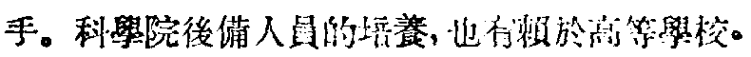
宫等學校與科學院必須密切合作，整個利學研究

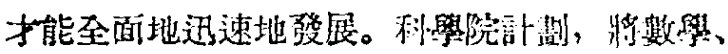

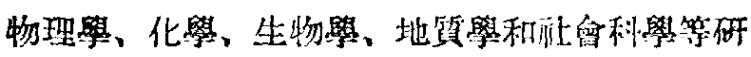
究部門集中於当都，土壤學，天文學主要在南京， 生理學、生物化學主要在上海，技術科學主要在 東北，而在西北則以水士保持、患林者牧及化工 石油篇主, 並且將根治黄河作篇將來酒北分院工 作的主要目標, 計劃在三個五年計劃之內基本上. 根治篇患千年的黄河氾传。這一分工，根㨜我國 的自然環境及已看的䃟究機構所在地址，是非常

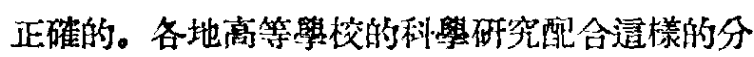
工來進行，在工作上是有方便的。晒北各漓等等 校的码究工作，必須畵可能和科學院晒北分院将 隶的工作，冾遖接或間接的聯系。我校的地犋、 地理、生物三系和水土保持及根治黃河等工作有 最第密切的關係。這三系將来的專阿化課程、期题

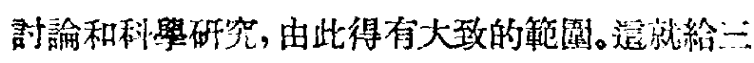

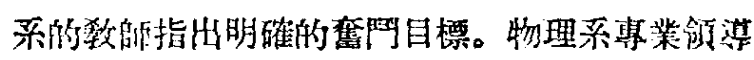

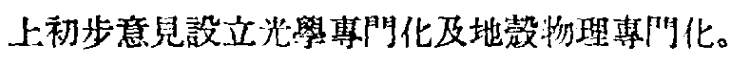
我們的意見是光學專門化㤫侮重結鼠炕學和金

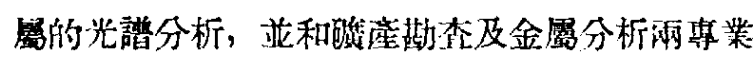
相絬合。地壱物理専門化以硼究物理探酸篇目標,

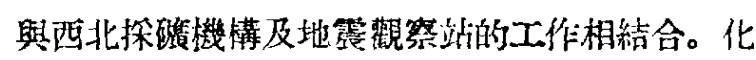
學系领導上初步意志, 将來没立磄石分析尃門化

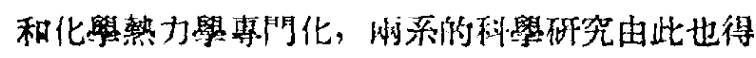

[下接 4 頁] 